\title{
A Comprehensive Approach to the Evaluation of Material Properties of S235JR Steel
}

\author{
Adam Kalavský ${ }^{1, *}{ }^{\text {, Peter Palička }}{ }^{1}$, Róbert Huňady ${ }^{1}$, Michal Kicko ${ }^{1}$ \\ Department of Applied Mechanics and Mechanical Engineering, Faculty of Mechanical Engineering, Technical University of Košice, Letná 9, 04200 \\ Košice; Slovakia
}

Abstract: The paper deals with the determination of mechanical and fatigue properties of S235JR steel, which is widely used in the engineering industry and also in other industries. The paper provides a brief overview of measurement procedures and basic mathematical formulations based on the standards ČSN EN ISO 6892-1 and ČSN 42 0368. The aim of the article is to provide a comprehensive view of the evaluation of material properties using not only conventional but also modern optical methods of mechanics, such as 3D digital image correlation or laser Doppler vibrometry. The output of the performed tests are material constants, mechanical properties in tension/pressure and fatigue characteristics under bending stress. The paper also presents the technique of estimating the Young's modulus of elasticity that is based on the experimental modal analysis. All results were obtained on a series of specimens made from an identical piece of material, making them ideal for defining a material card for different databases or FEM software.

Keywords: Young's modulus, Poisson's ratio, Proof Strength, S-N curve, tensile test, fatigue test, digital image correlation

\section{Introduction and Overview of Mathematical Theories}

Understanding the mechanical properties of the material is important in terms of designing components in the field of mechanical engineering. Mechanical properties are those that affect the mechanical strength and ability of the material to transform into the desired shape. The most common mechanical properties of the material include strength, toughness, hardness, brittleness, ductility, resilience, fatigue, etc. In this paper, attention is paid mainly to the strength and fatigue properties of steel S235JR.

\subsection{Strength}

It is the property of a material, which opposes the deformation or breakdown of material in presence of external forces or load. Materials we finalize for our engineering products must have the appropriate mechanical strength to be capable to work and withstand various mechanical forces or loads.

The ultimate tensile strength of the material is determined on tensile test rigs, which exerts an axial force on standard samples made of required material up to the total failure of the sample. Fig. 1 refers that the material of conventional structural steel subjected to the tensile test goes through three phases, namely - Elastic Deformation zone, Uniform Plastic Deformation zone and Non-Uniform Plastic Deformation zone.

In engineering practice, the most interesting is the first part of the diagram, which describes the elastic linear behaviour of the material. The engineers try not to exceed this area, as plastic deformations occur in the next part of the tensile curve and these are an undesirable effect in most processes.

When describing the linear region of an isotropic material (steel), we encounter two basic constants, which are Young's modulus $E$ and Poisson's ratio $v$. According to 


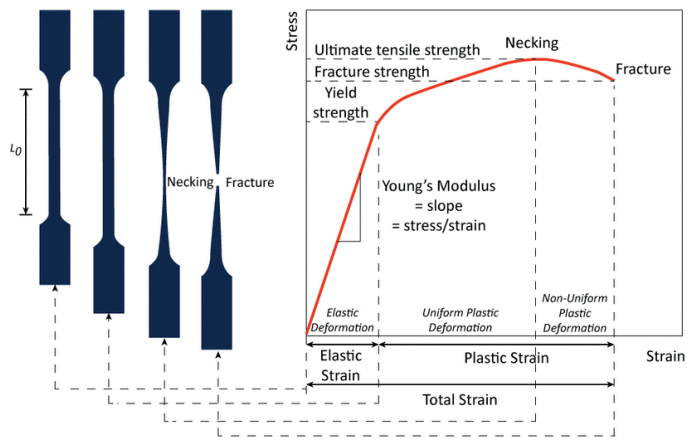

Figure 1: Tensile test diagram [1].

the standard ČSN EN ISO 6892-1, which the authors followed, Young's modulus is determined on the basis of

$E=\frac{1}{n} \cdot \sum_{i=1}^{n} \frac{\Delta \sigma_{i}}{\Delta \varepsilon_{i}}$

where $\Delta \sigma_{i}$ is the $i$-th stress change in the linear region and $\Delta \varepsilon_{i}$ represents the $i$-th change of the strain in the linear region, while taking into account $n$-samples of the measured output signal from the force gauge and the strain gauge or another strain measuring technique. According to the abovementioned standard, the prerequisites must be met:

- the Young's modulus of the selected segment must be constant on the evaluated part of the linear region,

- the selected segment for Young's modulus evaluation must be representative.

The standard also provides recommendations for the determination of Young's modulus:

- use of linear regression,

- lower limit: 10\% $R_{p 0.2}$ (Proof Strength),

- upper limit: $\sim 40 \% R_{p 0.2^{\prime}}$

- to obtain more accurate data on $R_{p 0.2}$ the line in the flexible region must be verified and, if necessary, recalculated for other limits [2].

To determine the Proof Strength, it is necessary to proceed by plotting a parallel line with the linear part of the tensile test curve which displacement in direction of deformations corresponding to $0.2 \%$ of the plastic elongation. The point, where this line intersects the tensile diagram (Fig. 2), corresponds to Proof Strength $\mathrm{R}_{\mathrm{p} 0.2}$.

\subsection{Fatigue}

Fatigue life estimation is one of the main problems in mechanical engineering. A large amount of damage to mechanical components occurs by cyclic stress. The fatigue process is influenced by a large number of factors, so for a

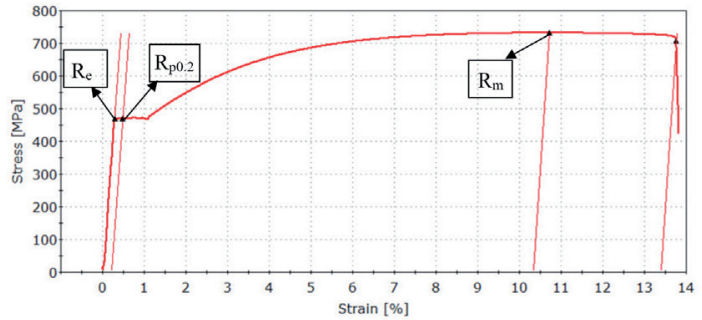

Figure 2: Proof Strength determination.

good description of the fatigue properties of the material and a reliable estimate of service life, in practice engineers must obtain the most accurate basic fatigue characteristics such as material fatigue curve at full reverse cycle with zero mean stress [3].

Historically, Albert was the first to notice the fatigue process (1838) [4], when designed a device that cyclically stressed mining chains and noticed that fatigue damage does not depend on overload but on the number of load cycles. Many other authors contributed to a better understanding of the fatigue process, including Fairbairn and Wöhler (1860), who conducted a systematic study of fatigue on railway wheelsets, compiled S-N curves, and the first suggest the concept of fatigue limit [5]. About 50 years after Fairbairn and Wőhler, Basquin (1910) formulated a mathematical description of S-N curve, which is widely used to these days. He proposed a relation in logarithmic coordinates

$$
N_{f} \cdot S_{f}^{m}=C
$$

where $N_{f}$ represents the number of cycles to failure at the stress level $S_{f}, C$ represents a constant and $m$ is an exponent of fatigue strength [6].

At present, there are a number of mathematical formulations for describing the S-N curve that express its shape, either linearly or otherwise. The authors of this paper decided to approximate or evaluate experimentally measured data using the standard ČSN 420368 [7], which defines the statistical estimate of fatigue test results for ferrous metals. The standard describes two approximation methods:

\section{» Linear method}

$S_{i}=\frac{\log \left(N_{i}\right)-c}{d}$

where $c, d$ are the coefficient given by

$c=\frac{1}{n} \sum_{j=1}^{n} \log \left(N_{j}\right)-d \cdot \overline{S_{j}}$, 


$$
d=\frac{n \cdot \sum_{j=1}^{n}\left(\log \left(N_{j}\right) \cdot S_{j}\right)-\sum_{j=1}^{n} S_{j} \cdot \sum_{j=1}^{n} \log \left(N_{j}\right)}{n \cdot \sum_{j=1}^{n} S_{j}^{2}-\left(\sum_{j=1}^{n} S_{j}\right)^{2}}
$$

where $\overline{S_{j}}$ is the arithmetic mean of the values of the measured stresses $S_{j}$, the symbols $N_{j}$ are marked with corresponding lifetimes in cycles, $n$ represents the number of measured data and

\section{" Nonlinear method}

$S_{i}=\left(\frac{N_{i}}{10^{c}}\right)^{\frac{1}{d}}+K$

where $c, d$ represent the coefficients of nonlinear regression and $K$ represents the minimum sampling variance obtained by the iterative method [7].

\section{Digital Image Correlation}

The Digital Image Correlation (DIC) method was used to measure the strains during the tensile test. The digital image correlation method is an optical method to measure strain and displacements, using the digital image registration technique. DIC provides the possibility to observe various phenomena during the deformation of an object of any shape, while it is applicable to the testing of a wide range of materials. Correlation systems are able to monitor a wide range of surface points, which allows to visualize the measured values over the entire monitored area [8]. The values of displacements are determined in the nodes of the virtual grid created automatically by the measurement software. After determining the initial surface 3D contour of the object and the vectors of displacements of individual points, it is possible to obtain fields of surface strains [9]. To increase the accuracy of the measurement, the authors used
3D correlation system Q-400 Dantec Dynamics. With this arrangement, it is possible to examine any objects from a size of several $\mathrm{mm}^{2}$ to several $\mathrm{m}^{2}$. The Q-400 system has two slow-speed cameras with a resolution of $5 \mathrm{Mpx}$, whose scanned speed at full sensor resolution is $2 \mathrm{fps}$. The cameras captured the analysed object from two different directions, which allowed to obtain a 3D contour of the object's surface. To obtain it, it is necessary to determine the internal and external calibration parameters of the cameras, such as the position of the focus, the curvature of the image and the position of both cameras. The calibration parameters are used to calculate the spatial coordinates of the contour points. The displacement field and strain field are determined by correlating the images captured over time, i.e. during loading. The first step is taken as a reference - representing the initial state. To correlate images, it is necessary to divide them into smaller pixels, so-called facets. The facets must be unique, so a stochastic speckle pattern is created on the surface of the object. In this case, a pre-printed elastic self-adhesive foil was used. The process of camera calibration, image acquisition, correlation and evaluation of results is provided by Istra4D software. The principle of 3D DIC method is explained in Fig. 3.

The position of each surface point is focused on a specific pixel in the image plane of the left and the right camera. During acquisition, the correlation system tracks the change in intensity of the grey value of each pixel. As the surface points move and the grey value of the pixels changes, it is much easier to trach the intensity of a set of pixels (i.e. facet) than the intensity of each of them. If internal and external calibration parameters are known, the system is able to determine the transformation coordinates $x_{t}$
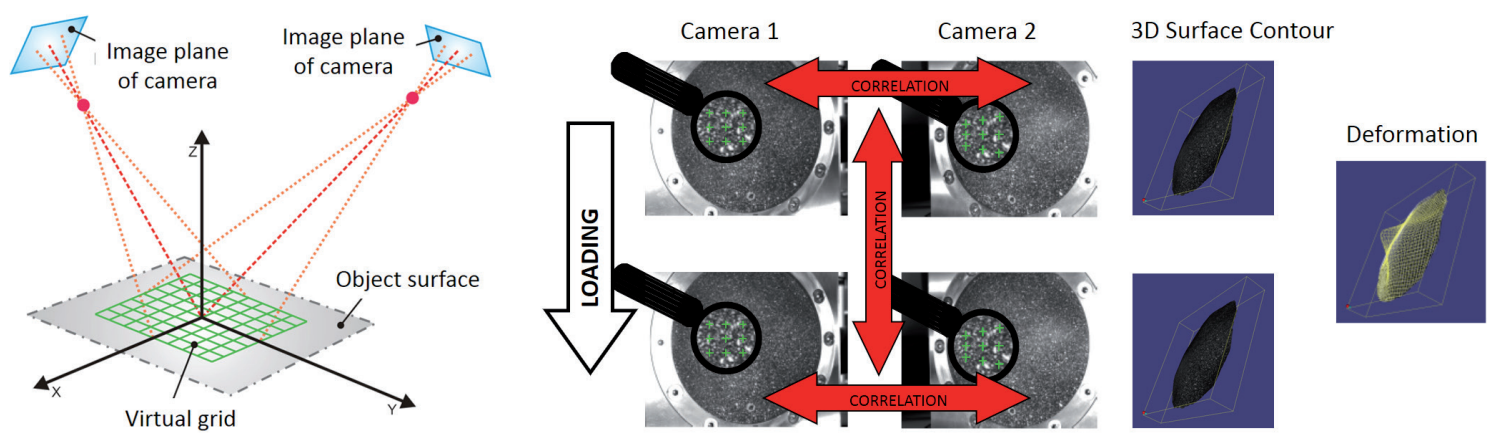

Figure 3: Basic principle of 3D DIC method [8]. 
and $y_{t}$ of each facet. The Dantec Dynamics systems use the algorithm working on the pseudo-affinity transformation for that reason. If $a_{0}, a_{1}, a_{2}, \ldots, a_{7}$ are the transformation parameters of potential displacement, tension, shear or torsion of the facet (see Fig. 4), then $x_{t}$ and $y_{t}$ are calculated as

$$
\begin{aligned}
& x_{t}\left(a_{0}, a_{1}, a_{2}, a_{3}, x, y\right)=a_{0}+a_{1} x+a_{2} y+a_{3} x y \\
& y_{t}\left(a_{4}, a_{5}, a_{6}, a_{7}, x, y\right)=a_{4}+a_{5} x+a_{6} y+a_{7} x y
\end{aligned}
$$

Transformation parameters are determined using minimization of the difference between the value of intensity in actual image $G_{2}(x, y)$ and the previous one $G_{1}(x, y)$ as follows:

$\min _{a_{0}, \ldots, a_{7}, g_{0}, g_{1}} \sum_{x, y}\left\|G_{1}(x, y)+g_{0}-g_{1} \cdot G_{2}\left(x_{t}(x, y), y_{t}(x, y)\right)\right\|(7)$

where $g_{0}$ and $g_{1}$ represent the illumination corrective parameters.

If the coordinates of all points of the 3D surface contour are determined for all time steps, then it is possible to calculate the displacement field and the field of surface strains.
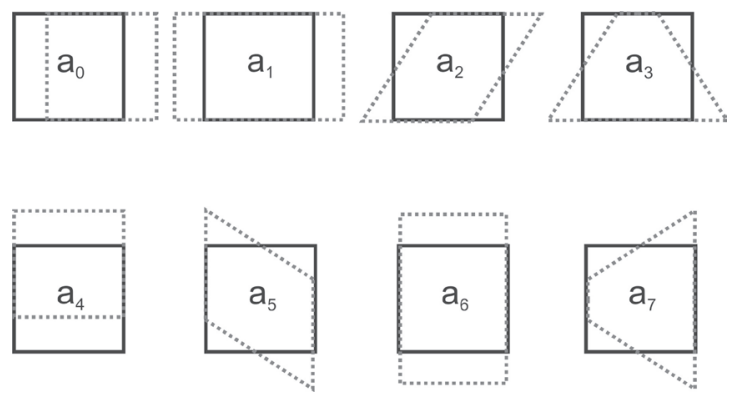

Figure 4: Modes of pseudo-affinity transformation.

\section{Experimental Section}

The experiments were performed with 20 normalized fatigue specimens (Fig. $5 a$ ) and 5 normalized tensile test specimens (Fig. 5b). The specimens were made of the steel S235JR, the chemical composition of which is given in Tab 1.
The authors decided to analyse the material and fatigue properties of S235JR steel mainly due to its versatile use in many engineering applications such as the construction of industrial equipment (or equipment elements), supporting structures, oil and gas platforms, cars, bridges and other structures. S235JR boards are also often used for shipbuilding. The S235JR is an extremely flexible material and is highly preferred by engineers looking to maximize structural strength with minimal weight. S235JR is suitable for welding, screw connections and riveting. It is easy to weld and bend and suitable for non-critical constructions. Its machinability is similar to mild steel.

Table 1. Chemical composition of S235JR [\%] [10].

\begin{tabular}{|c|c|c|c|c|c|c|c|}
\hline $\mathrm{C}$ & $\mathrm{Mn}$ & $\mathrm{Si}$ & $\mathrm{P}$ & $\mathrm{S}$ & $\mathrm{N}$ & $\mathrm{Cu}$ & Other \\
\hline $\max$. & $\max$. & - & $\max$. & $\max$. & $\max$. & $\max$. & --- \\
0,17 & 1,40 & & 0,04 & 0,04 & 0,012 & 0,55 & \\
\hline
\end{tabular}

\subsection{Tensile test}

Tensile tests were performed according to the ČSN EN ISO 6892-1 standard. The specimens were loaded using tensile test rig Inspekt 5 Hegewald\&Peschke, which can produce the maximum tensile force $5 \mathrm{kN}$ [11].

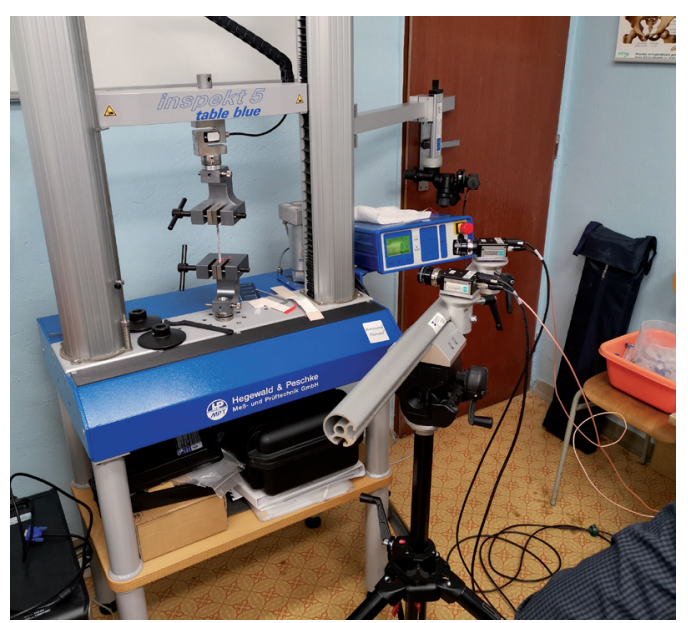

Figure 6: Tensile test configuration.
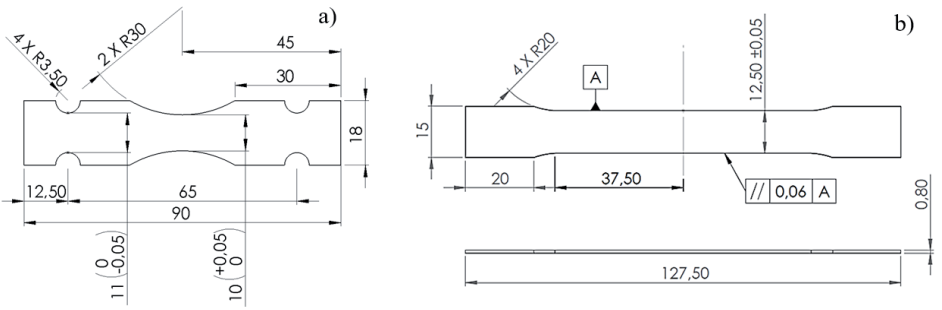

Figure 5: a) Fatigue specimen, b) tensile test specimen. 
For the purpose of evaluating and determining material properties, only tensile strength data were required. The evaluation of material properties was realized in an analytical way using known relations of the continuum mechanics. The tensile stress was calculated based on the relationship

$\sigma=\frac{F}{A}$

where $F$ is a loading (tensile) force and $A_{0}$ is the initial cross-sectional area of the sample. Fig. 7 shows the dependence of the tensile force on the displacement of the traverse during the tensile test.

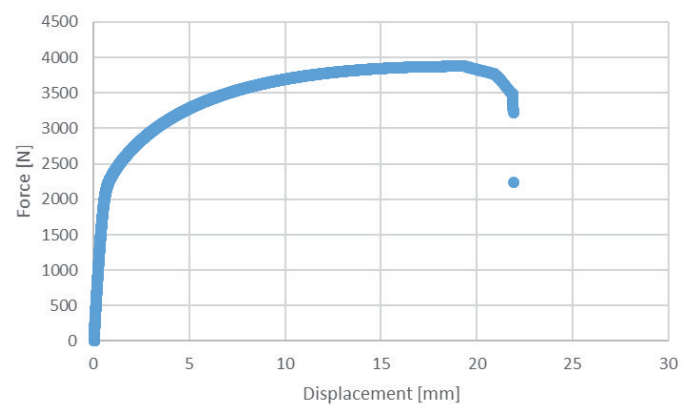

Figure 7: Dependence of force on displacement during tensile test.

As mentioned, the Q-400 3D correlation system was used to measure displacements and strains. Fig. 7a shows the test sample and the region of interest that was included in the evaluation of the measurement.

The relative elongation of the test sample was determined by the method of two lines [12], which were determined on the surface of the specimen in accordance with the procedure given in the standard. Lines were defined as virtual line sensors, measuring their relative distance. The longitudinal strain $\varepsilon$ was then calculated from the relationship

$\varepsilon=\frac{\Delta l}{l_{0}}$

where $\Delta l$ is the elongation of the specimen due to tensile loading, and $l_{0}$ is the initial distance of the lines (before loading).

The tensile test was performed until the sample was torn. Fig. $7 \mathrm{~b}$ shows the strain field at the instant of its failure. The rupture occurred approximately in the middle of the sample. Due to the interruption of the speckle pattern, the facets near this area were lost. (a)

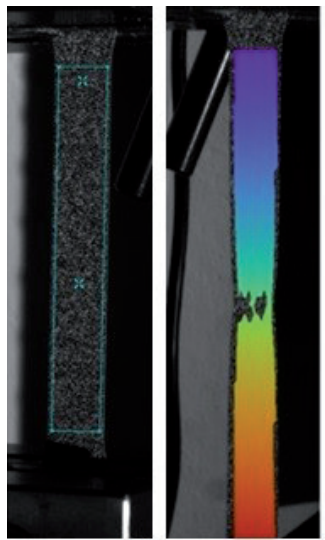

(b)

Figure 8: a) Correlation zone with starting points. b) Displacement field at the instant of failure.

The evaluation of the deformation was followed by plotting the stress-strain curve (see Fig. 9a), from which the Young's modulus of elasticity was evaluated in the linear region. Since a higher sampling frequency was set in the tensile test than in the measurement of deformation using DIC, it was necessary to synchronize the deformation values with the stress values. Young's modulus was determined by linear regression as recommended by the norm. From the linear region of the stressstrain curve, the truncated region (red rectangle in Fig. 8a) was evaluated. The resulting line and the equation expressing its slope are shown in Fig. 9b. The value of Young's modulus was determined to be approximately $210 \mathrm{GPa}$.

The ultimate tensile strength $R_{\mathrm{m}}$ (red dot in Fig. $9 a)$ was determined according to the relation

$R_{m}=\frac{F_{m}}{A_{0}}$

where $F_{\mathrm{m}}$ is the value of the breaking force and $A_{0}$ is the initial cross-sectional area of the specimen. The ultimate tensile strength of the material is $387 \mathrm{MPa}$.

The value of the Yield strength $R_{\mathrm{p} 0.2}$ was also determined from the stress-strain curve according to the standard. A line parallel to the linear region of the stress-strain curve intersected through 0.002 strains (Fig. 9). At the red point where this parallel crossed the stress-strain curve, the value of the Yield strength was determined to be $235 \mathrm{MPa}$.

In Istra4D, rectangular virtual strain gauge was defined in the middle of the specimen. The strain values averaged over its surface in the longitudinal and transversal direction was used to calculate Poisson's ratio of the material. 

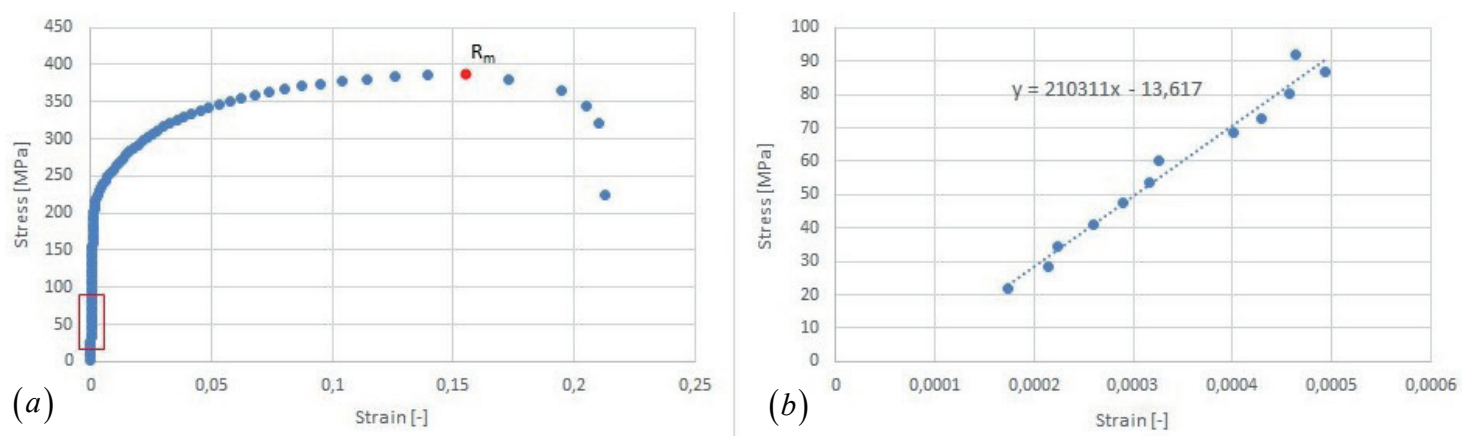

Fig. 9 a) Stress-strain diagram. b) Linear regression of the elastic region of the stress-strain diagram.

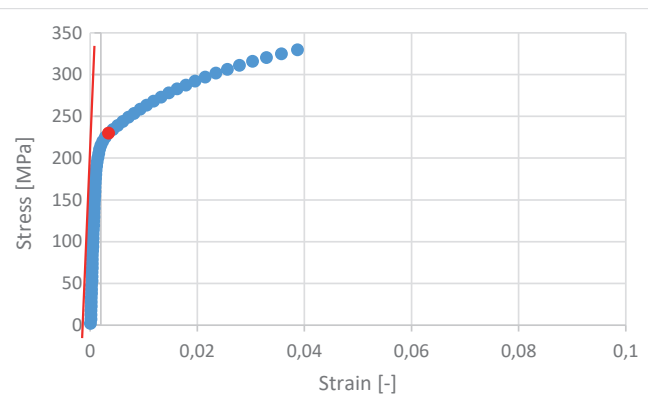

Figure 10: Yield strength $R_{p 0,2}$

Fig. 10 shows the value of the Poisson's ratio in the selected loading steps representing the area of linear elastic deformation. The resulting Poisson's ratio value (0.3056) was obtained by averaging the values in the individual steps.

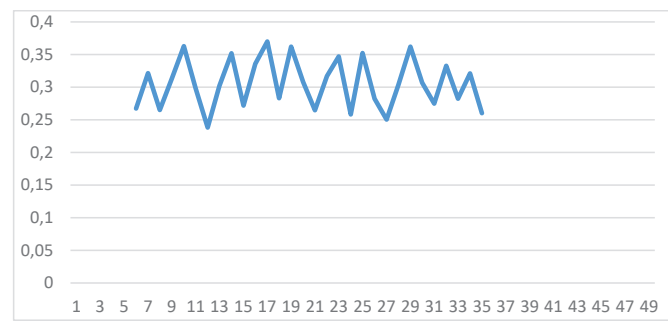

Figure 11: The value of the Poisson's ratio in individual steps.

\subsection{The estimation of Young's modulus from natural frequencies}

As an alternative to the tensile test, a method based on the well-known theory of beam vibration was used to determine the Young's modulus. The main assumption is the knowledge of the natural frequencies of bending modes of the analysed beam. These frequencies can be obtained by experimental modal analysis. Then we use the following equation to estimate the Young's modulus

$$
\omega^{2}=(\beta \ell)^{2} \sqrt{\frac{E J}{\rho A \ell^{4}}}
$$

where $E$ is Young's modulus, $J$ is the second moment of a cross section area $A, \rho$ is a density of material, $\ell$ is a length of beam, and $\beta$ is a constant, which is determined for the individual modes and depends on boundary condition [13].

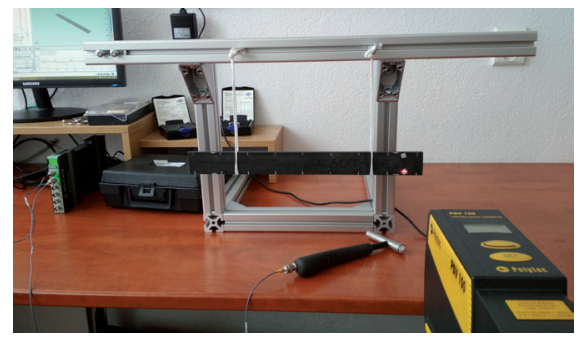

Figure 12: Experimental configuration.

The object of measurement was a free-free beam of a length $401 \mathrm{~mm}$ and rectangular cross section 40x8 mm. The beam was made of S235JR steel. A free supporting was realized by two elastic ropes (see Fig. 12). The structure was excited at 18 points by impact hammer Bruel\&Kjaer 8206 with aluminium tip. The responses were measured at one point by laser Doppler vibrometer Polytec PDV100. Fig. 13 shows Complex Mode Indicator Function (CMIF) that was obtained by singular value decomposition of the FRF matrix. In the frequency range up to $3.2 \mathrm{kHz}$, six modes were identified (see Tab. 2). The corresponding mode shapes of vibration are shown in Fig. 14.

For the calculation of Young's modulus, the second moment of cross section area and density of material had to be calculated:

$$
\begin{aligned}
& J=\frac{b h^{3}}{12}=\frac{0.04 \cdot 0.008^{3}}{12}=1.7067 \cdot 10^{-9} \mathrm{~m}^{4}, \\
& \rho=\frac{m}{V}=\frac{1.005}{1.2832 \cdot 10^{-4}}=7832 \mathrm{~kg} \cdot \mathrm{m}^{-3}
\end{aligned}
$$


where $m$ is the mass of the beam determined by weighting. The values of Young's modulus calculated on the basis of natural frequencies of bending modes are listed in Tab. 2. The average value is $209.94 \mathrm{GPa}$.

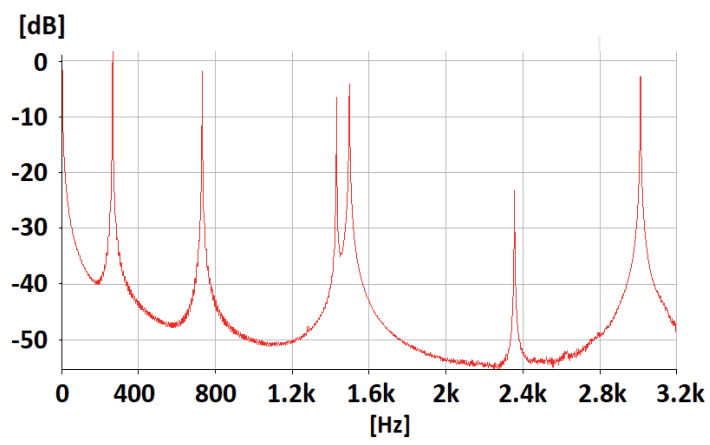

Figure 13: CMIF plot of the analysed beam.

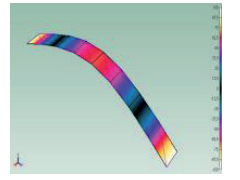

1. mode

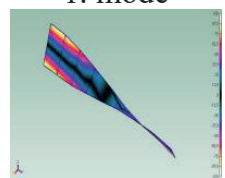

4. mode

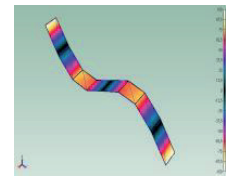

2. mode

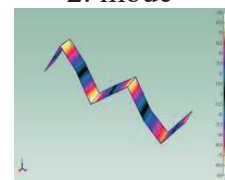

5. mode

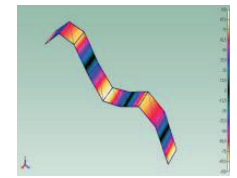

3. mode

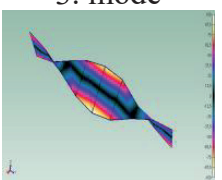

6. mode
Figure 14: The first six mode shapes of the beam.

\subsection{Fatigue test}

To determine fatigue life, 20 standard specimens without notches were used (Fig. 15a). These specimens were made from a single piece of material and oriented in the same direction to ensure the best possible concordance of the test set. All had a surface finish by polishing and chamfered (smooth) edges to avoid side effects that may affect the result of the experiment. These boundary effects are analysed in detail in the literature [13-15].

For experimental measurements, a bending fatigue test rig by SCHENCK for small specimens was used (Fig. 15b). As it was an older device, it was supplemented with new software recording the number of cycles achieved and automatically shutting down the machine after breaking the specimen. The software works together with hardware equipment (Fig. 16) and it was developed at the Department of Applied Mechanics and Mechanical Engineering, Faculty of Mechanical Engineering, Technical University of Košice [16].

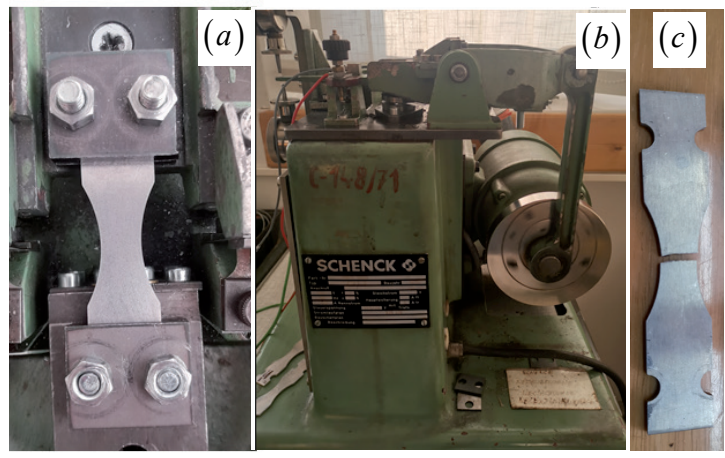

Figure 15: a) Embedded specimen prepare for fatigue test. b) Schenck - fatigue testing machine. c) Damaged specimen after the fatigue test.

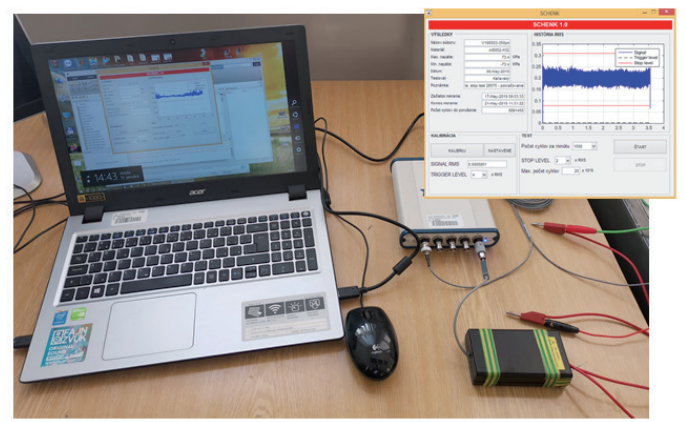

Figure 16: Software and hardware support equipment for the fatigue machine.

Table 2. Modal parameters of the beam and calculated values of Young's modulus.

\begin{tabular}{|c|c|c|c|c|c|}
\hline Mode & Type & Natural frequency (Hz) & Damping (\%) & $\beta_{i} \ell$ & $\begin{array}{c}\text { Young's } \\
\text { modulus (GPa) }\end{array}$ \\
\hline 1 & 1. bending & 265.44423 & 0.14874 & 4.730041 & 211.01 \\
\hline 2 & 2. bending & 731.27606 & 0.03655 & 7.853205 & 210.76 \\
\hline 3 & 3. bending & 1429.9689 & 0.02958 & 10.99561 & 209.69 \\
\hline 4 & 1. torsional & 1496.9447 & 0.07209 & - & - \\
\hline 5 & 4. bending & 2355.8112 & 0.02658 & 14.13717 & 208.28 \\
\hline 6 & 2. torsional & 3010.7528 & 0.01926 & - & - \\
\hline
\end{tabular}


Fig. 14 shows a pair of S-N curves obtained by a linear and a non-linear approximation method. A simple Matlab script using the mathematical relations mentioned in Section 1 was used for that purpose. It can also be seen that the test group was divided into 4 stress levels with 5 tests performed at each level, which is according to Papuga [17] the minimal amount of points for a good statistical description of the fatigue curve. For a better overview of the obtained results, Tab. 3 is provided, which gives the exact number of the cycles to failure of each specimen used in fatigue analysis.

Table 3. S-N curve raw data for material S235JR.

\begin{tabular}{|c|c|c|c|c|c|}
\hline No & $\begin{array}{c}\text { Stress } \\
\text { amplitude } \\
{[\mathrm{MPa}]}\end{array}$ & $\begin{array}{c}\text { Number of } \\
\text { cycles }\end{array}$ & No & $\begin{array}{c}\text { Stress } \\
\text { amplitude } \\
{[\mathrm{MPa}]}\end{array}$ & $\begin{array}{c}\text { Number } \\
\text { of cycles }\end{array}$ \\
\hline 1 & 185 & 1188975 & 11 & 215 & 318800 \\
\hline 2 & 185 & 1075025 & 12 & 215 & 300975 \\
\hline 3 & 185 & 750200 & 13 & 215 & 272125 \\
\hline 4 & 185 & 649650 & 14 & 215 & 181875 \\
\hline 5 & 185 & 622175 & 15 & 215 & 176750 \\
\hline 6 & 200 & 973575 & 16 & 235 & 191850 \\
\hline 7 & 200 & 585350 & 17 & 235 & 148075 \\
\hline 8 & 200 & 552600 & 18 & 235 & 124825 \\
\hline 9 & 200 & 458325 & 19 & 235 & 101300 \\
\hline 10 & 200 & 415725 & 20 & 235 & 94750 \\
\hline
\end{tabular}

\section{Conclusions}

The paper deals with the determination of mechanical and fatigue properties of S235JR steel, which can be used for comparison with other existing material databases. In engineering practice, we often encounter insufficient description of material data. The values may differ from each other, and it is therefore appropriate to present all the results obtained, which can statistically support further research. In addition, in this paper, all tests and measurements are performed on the specimens made of identical material, so the result is a set of data characterizing the analysed steel comprehensively. Such a data set can advantageously be used to define a material card in FEM calculations.

The properties were determined experimentally in agreement with the methodologies given by ČSN EN ISO 6892-1 and ČSN420368 standards. Two experimental measurements were performed within the study: the tensile test at room temperature with constant loading rate and the fatigue test in bending without mean stress value at full reverse cycle.

Five standardized samples were used for the tensile test, which provided a sufficient statistical data for the evaluation of the test recommended by ČSN EN ISO 6892-1 standard. The measured tensile forces were converted to tensile stresses using well known relations of the mechanics of the deformable body. Deformations on the specimen were measured using DIC system and subsequently processed in Istra4D program. Strains were evaluated in two ways, directly (implemented by a function in the program) and on the basis of a two-line method.
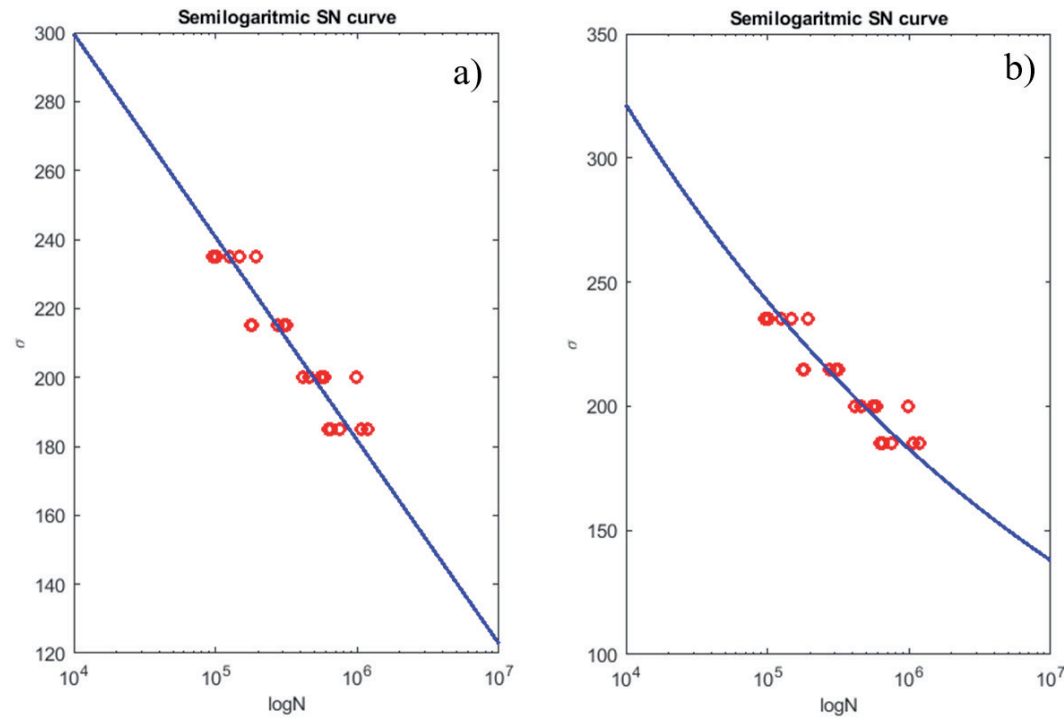

Figure 17: a) Linear and b) nonlinear approximation of S-N curve by ČSN-420368. 
Table 4. S-N curve raw data for material S235JR.

\begin{tabular}{|c|c|c|c|c|c|c|c|}
\hline \multicolumn{8}{|c|}{ Material Properties } \\
\hline \multicolumn{2}{|c|}{ Young's modulus } & \multicolumn{2}{|c|}{ Poisson's ratio } & \multicolumn{2}{|c|}{ Yield Strength } & \multicolumn{2}{|c|}{ Ultimate Tensile Strength } \\
\hline \multicolumn{2}{|c|}{$210 \mathrm{GPa}$} & \multicolumn{2}{|r|}{0.306} & \multicolumn{2}{|c|}{$235 \mathrm{MPa}$} & \multicolumn{2}{|c|}{$387 \mathrm{MPa}$} \\
\hline \multicolumn{8}{|c|}{ Fatigue Properties } \\
\hline \multicolumn{3}{|c|}{ Basquin coeff. } & \multicolumn{2}{|c|}{ Lin. regression coeff. } & \multicolumn{3}{|c|}{ Non-Lin.regression coeff. } \\
\hline$m$ & \multicolumn{2}{|l|}{$C$} & $a$ & $b$ & $c$ & $d$ & $K$ \\
\hline 8.1886 & \multicolumn{2}{|c|}{$3.1690 \mathrm{e} 24$} & 9.0807 & -0.0170 & 24.2530 & -8.0863 & 1.8500 \\
\hline
\end{tabular}

The outputs of the Istra4D program showed a very good similarity with the values obtained by the analytical approach using the two-line method. It can be stated that both methods can be used to determine the mechanical properties of materials. The value of the Young's modulus was verified by an alternative method based on modal analysis and theory of beam vibration. This approach provides a very accurate estimate and can be applied to other types of materials.

Fatigue tests were performed on 20 specimens to obtain the S-N curves (5 measurements for each of the 4 stress levels). The results obtained by the method of linear and nonlinear approximation are suitable for HCF. Lifespans of 10,000 cycles and more can be considered relevant. It should be noted that the extrapolated data in the linear approximation may not correspond to reality. Since the definition of the S-N curve according to Basquin often occurs in computational software, the authors also provide an estimate of the fatigue strength exponent and the constants of the Basquin equation. All results of the experimental measurements are summarized in Tab.4. As can be seen in other publications $[18,19]$, the fatigue properties differ slightly from the measured experimental data. The article provides a whole set of measured data from fatigue experiments, which can be approximated as needed by other methods (eg Kohout-Vechět, Sendeckyj).

\section{Acknowledgments}

This work was supported by the Scientific Grant Agency of the Slovak Republic under grant VEGA 1/0355/18.

\section{References and Notes}

1. Yalcin D (2017) How do different specimen geometries affect tensile test results?

2. Standard ČSN EN ISO 6892-1: "Metallic materials — Tensile testing - Part 1: Method of test at room temperature"

3. Kalavský A, Huňady R, Hagara M, Palička P (2021) Determination of fatigue material curve at fully reverse cycle without mean stress for aluminium alloy ENAW 5754 - H12. Novus Scientia 28:1-4

4. Albert WAJ (1838) Über Treibseile am Harz. Archiv für Mineralogie, Geognosie, Bergbau und Hüttenkunde 10:215-234

5. Schütz W (1996) A history of fatigue. Engineering Fracture Mechanics 54:263-300. https://doi.org/10.1016/00137944(95)00178-6

6. Basquin $\mathrm{OH}$ (1910) The exponential law of endurance test. Proceedings of the American Society for Testing and Materials 10:625-630

7. Standard ČSN 42 0368: "Metal testing. Metal fatigue tests. Statistical evaluation of metal fatigue test results"

8. Trebuňa $F$, Pástor $M$, Huňady $R$, Frankovský $P$, Hagara $M$ (2017) Optické metódy v mechanike, TUKE, Košice

9. Trebuňa F, Hagara M, Schrőtter M (2013) The use of optical methods by investigation of various solid mechanics problems. Transfer inovácií 25:58-62

10. S235JR Steel Grade, Mechanical Properties, Chemical Composition, Grade Equivalent. http://www.b2bmetal.eu/ en/pages/index/index/id/141/. Accessed 23 Jan 2021

11. Universal testing machine Inspekt table $5 \mathrm{kN}$. https://www. hegewald-peschke.com/products/industry-and-material/ product-detail/universal-testing-machine-inspekt-table-5kn.html. Accessed 23 Jan 2021

12. Palička P, Kal'avský A, Huňady R, et al (2021) Determination of material properties of aluminium alloy using $3 \mathrm{D}$ digital image correlation. Novus Scientia 28:1-5

13. Trebuňa F, Šimčák F (2004) Odolnost prvkov mechanických sústav. TUKE, Košice

14. Bayoumi MR, Abdellatif AK (1995) Effect of surface finish on fatigue strength. Engineering Fracture Mechanics 51:861870. https://doi.org/10.1016/0013-7944(94)00297-U

15. KlotzT, Lévesque M, Brochu M (2019) Effects of rolled edges on the fatigue life of shot peened Inconel 718. Journal of 
Acta Mechanica Slovaca

Journal published by Faculty of Mechanical Engineering - Technical University of Košice

Materials Processing Technology 263:276-284. https://doi. org/10.1016/j.jmatprotec.2018.08.019

16. Kalavský A, Huňady R, Lengvarsky P (2020) Spectral fatigue life for simple notched component. Manufacturing Technology 20:612-616. https://doi.org/10.21062/ mft.2020.073

17. Papuga J, Kal'avský A, Lutovinov M, et al (2021) Evaluation of data sets usable for validating multiaxial fatigue strength criteria. International Journal of Fatigue 145:1-15. https:// doi.org/10.1016/j.ijfatigue.2020.106093

18. Kepka M., Kepka M. Jr. (2018) Using design s-n curves and design stress spectra for probabilistic fatigue life assessment of vehicle components. International Conference IntegrityReliability-Failure. Lisabon. 373- 384.

19. Tomaszewski T., Strzekecki P. (2016) Study of the Size Effect for Non-Alloy Steels S235JR, S355J2+C and Acid-Resistant Steel 1.4301. AIP Conference Proceedings 1780:1-8. doi: 10.1063/1.4965940. 